Please quote as: Bretschneider, U.; Leimeister, J. M. \& Mathiassen, L. (2015): ITenabled Product Innovation: Customer Motivation for Participating in Virtual Idea Communities. In: International Journal of Product Development, Ausgabe/Number: 2, Vol. 20, Erscheinungsjahr/Year: 2014. Seiten/Pages: 126-141. 


\title{
IT-enabled product innovation: customer motivation for participating in virtual idea communities
}

\author{
Ulrich Bretschneider* \\ Information Systems, \\ University of Kassel, \\ 34121 Kassel, Germany \\ Email: bretschneider@uni-kassel.de \\ *Corresponding author
}

\author{
Jan Marco Leimeister \\ Information Systems, \\ University of Kassel, \\ 34121 Kassel, Germany \\ and \\ Institute of Information Management, \\ University of St. Gallen, \\ St. Gallen, Switzerland \\ Email: leimeister@uni-kassel.de \\ Email: janmarco.leimeister@unisg.ch
}

\section{Lars Mathiassen}

Computer Information Systems,

J. Mack Robinson College of Business,

Georgia State University,

Atlanta, GA 30303, USA

Email: 1mathiassen@ceprin.org

\begin{abstract}
Virtual idea communities (VICs) such as Dell's 'Ideastorm' are very popular in practice. In VICs, customers of firms can submit ideas to support product innovation. This customer-based ideation is not new. Customers have been brought together in lead-user-workshops or focus-groups since the 1980s to support product innovation. However, VICs represents a new form of ITmediated ideation with customers. While extant research has provided insights into customers' motives for participating in traditional ideation, we know little about the motivations that drive customer participation in this new form of ITenabled ideation. Based on a survey of customer motivations for participation, we found evidence for motives that arise directly due to the VIC's IT-ability to support visualisation of customer ideas, to give feedback on ideas, and to support customers' social interactions. As a result, VICs are perceived as a way to demonstrate personal capabilities, for getting recognition, and for facilitating social interaction.
\end{abstract}

Keywords: virtual idea community; open innovation; crowdsourcing; motivation; ideation; new product development; customer involvement; idea management system. 
Reference to this paper should be made as follows: Bretschneider, U., Leimeister, J.M. and Mathiassen, L. (2015) 'IT-enabled product innovation: customer motivation for participating in virtual idea communities', Int. J. Product Development, Vol. 20, No. 2, pp.126-141.

Biographical notes: Ulrich Bretschneider is a Senior Researcher in the Department of Information Systems at the University of Kassel. His current research interests include crowdsourcing for innovation/open innovation and crowdfunding. Much of his work concentrates on the design of virtual idea communities.

Jan Marco Leimeister is a Full Professor and Director of the Institute of Information Management (IWI-HSG), University of St. Gallen and he is Chair for Information Systems at Kassel University, Germany. Furthermore, he is Director of the Interdisciplinary Research Center for Information System Design (ITeG) at Kassel University. His teaching and research areas include digital business, IT innovation management, service science, collaboration engineering, ubiquitous computing and crowdsourcing. He serves on the editorial board of various international journals and is regularly member of programme committees of international conferences in the field of Information Systems.

Lars Mathiassen is Georgia Research Alliance Eminent Scholar, Professor at the Computer Information Systems Department and Co-Founder of Center for Process Innovation at Robinson College of Business, Georgia State University. His research focuses on development of information services, on IT-enabled innovation of business processes and on management and facilitation of organisational change processes. He approaches innovation and improvement initiatives with a strong focus on people skills and collaboration while at the same time emphasising adoption of state-of-the-art technologies and methods. The philosophy underlying much of his research is discussed in 'Reflective Systems Development'.

\section{Introduction}

Virtual Idea Communities (VICs) are a new phenomenon in business. These communities, in which distributed groups of individual customers focus on voluntarily sharing and elaborating innovation ideas, are used by firms to integrate customers into ideation for new product development rooted in Chesbrough's (2003) open innovation paradigm or according to the more general crowdsourcing principle (Afuah and Tucci, 2012). Based on this paradigm, firms transcend their boundaries in order to engage other resources in developing ideas for innovation (Chesbrough, 2003; Afuah and Tucci, 2012). In this context, customers are seen as a key resource as they often have high product expertise as well as experience and creativity potential gained by regular product usage (Magnusson et al., 2009; Zogaj and Bretschneider, 2012). In this context, Öberg (2010) describes customers as initiators, as co-producers and an inspiration for business development.

The idea that firms benefit from customer-based, collaborative ideation is not new per se. Since the 1980s, small groups of customers have been brought together in face-to-face 
settings to support new product development (Zogaj and Bretschneider, 2012). Von Hippel's (1986) 'lead user approach' and focus groups are examples of such customer integration (Fern, 1982; Moors et al., 2008; Zogaj and Bretschneider, 2012). In workshop formats like these, a small group of typically five to ten customers is called together in order to develop ideas towards an existing product or towards opinions, beliefs and attitudes regarding new products. Questions are asked in an interactive group setting by company employees to stimulate ideation.

Motives for participating in ideation workshops have been exhaustively researched. First, there is the need motive. Customers feel that by participating in product development, they can lobby and influence the firm to incorporate certain product features that are highly valuable in the customer's own context (von Hippel, 1986). This has often been evidenced in the enterprise software product market, where customers from a particular industry actively contribute to product development efforts in order to ensure that their specific needs are met by a new product (Hoch et al., 1999). Closely related to the need-motive is the product improvement motive. Hoch et al. (1999) found that customers are willing to participate in firms' ideation processes because they want to accentuate the necessity of improving the functionality or a defect of the underlying product. Third, there is the learning motive. Often, customers engage in new product development to gain knowledge from participating in ideation workshops (Thomas and Dunn, 1994). Customer involvement enhances their knowledge about the product, as well as about the underlying technologies, which, in turn, enables them to use the product in a more comprehensive manner, thereby increasing the potential benefit from product usage (Nambisan, 2002). A further reason for participating in traditional ideation workshops is the fact that customers receive monetary compensation (Mills, 1986), although this has been described not to be the most relevant motive (Bilgram et al., 2008). Finally, customers participate in product development not only because they find it intrinsically attractive, but also because it satisfies their creative urges and their product-related curiosity (Bateson, 1983; Nambisan, 2002). So, some customers have fun generating and collaboratively elaborating ideas (fun motive); others may understand generating and elaborating ideas as an intellectual stimulation (intellectual stimulation motive).

By implementing VICs, firms move customer-based, collaborative ideation onto the internet. Many well-known companies, including Dell, Starbucks, Google, SAP, Intel and BMW, have established such internet-based ideation forums (Di Gangi and Wasko, 2009). In VICs, customers can post their ideas, vote for and comment on other customers' ideas, and help improve ideas in a collaborative manner, similar to what is currently achieved in lead user workshops and focus groups. Firms organise VICs from initial community building to continuous community management. This allows them to control the community throughout, from moderation of the ideation to non-restrictive use of its idea outcome. VICs are supported by IT- and internet-mediated idea management systems, which meet all ideation requirements according to Sandström and Björk (2010), e.g. functionalities for idea uploading, storage, commenting, elaboration and visualisation. To sum up, VICs enable a paradigm shift from real-world ideation to virtual ideation with customers.

By shifting customer ideation onto the internet, firms profit from organisational benefits. First, inviting customers into VICs is less complex than organising face-to-face workshops. Once the VIC is established, firms can constantly get back to the customer 
knowledge base. Furthermore, the IT-based idea management systems underlying VICs help firms to evaluate and select the most promising customer ideas (Sandström and Bjork, 2010). Second, compared to lead user workshops and focus groups, VICs can help firms attain access to a much broader customer base and customer knowledge base (Leimeister, 2012; Leimeister, 2014; Leimeister et al., 2009; Zogaj and Bretschneider, 2012). This considerably raises the likelihood of identifying a number of promising ideas for product development.

VICs also offer benefits for customers, i.e. when engaging in a VIC, customer ideas are visible to a broad group of peers. This makes it possible for customers to get recognition from peers or to profile themselves. It is therefore reasonable to hypothesise that IT-enabled customer ideation brings out new forms of customer motivation. However, to date, little is known about the motivations for participating in VICs. As a result, we pose the following research questions:

- Are motivation factors that are known from lead user workshops and focus groups relevant in VICs as well?

- Are there other motivations that arise because customer ideation is enabled by IT via the internet?

By giving concrete answers to these research questions, our research will provide valuable insights for firms regarding how to create effective incentive strategies that attract these motives. These, in turn, will lead to higher amounts of customer participating and contributing ideas to VICs.

Against this backdrop, our paper aims at empirically identifying customer motives for participating in VICs, especially motives that are directly ascribed to customer ideation being IT-enabled. The argument is organised as follows. In the next section, we derive IT-enabled motives from open source motivation research. With an online survey, we then query our theoretically identified motives as well as the above-mentioned motives for participating in offline ideation workshops amongst customers ${ }^{1}$ participating in SAPiens, the VIC of the ERP software producer SAP. We analyse the empirical data with the help of factor analysis. Thereafter, we identify a set of six empirically tested motives. In the last section, we discuss our findings in relation to extant research on customer-based ideation.

\section{Literature review and propositions}

Human motivation has been discussed prominently in the field of open source community research. Various motives are examined that make open source software programmers participate in open source software projects. As open source software communities are basically comparable to VICs, it is worth checking if motives examined in the open source domain could be extracted to our case. So, we conducted a literature review. The most relevant empirical studies out of the field of open source research that deal with programmers' motives for participation in open source communities were examined focusing on examined motivation factors and analysing which of them are appropriable for the use of our own survey. Based on the insights of this research, we found three further motives which could be applied to our case. We built our propositions as follows. 
Hars and $\mathrm{Ou}$ (2002) and Hertel et al. (2003) found that open source software programmers participate in open source software communities to demonstrate their capabilities and skills through submission of code. Audiences of such signals are other programmers, but mainly software companies which often engage in such projects. Participating in open source projects, therefore, can be a good channel for selfadvertisement/self-marketing for programmers seeking new job opportunities. Applied to VICs, people may consider participating in idea communities as an effective way to demonstrate their capabilities and skills shown through their submitted ideas. Their achievements in idea communities can be used to demonstrate competence to the organiser of the idea community or others. Reactions by thirds may be caused on the basis of submitted ideas. Participating in an idea community, therefore, can be a good channel for self-advertisement for those seeking new job opportunities. This phenomenon is mainly discussed in the field of open source motivation as the self-marketing motive (Hars and Ou, 2002; Hertel et al., 2003). Thus, we offer the following proposition.

Proposition 1: Customers use firms' VICs to demonstrate their capabilities and skills by displaying and sharing ideas (self-marketing motive).

Another motive discussed in open source motivation surveys is the so-called recognition motive (Hars and Ou, 2002; Hertel et al., 2003). Recognition contains expected reactions of significant others, such as other programmers. Motivation to contribute to an open source community should be higher the more positive the expected reactions of significant others are, weighted by the perceived importance of these significant others. This relation is formally expressed as a multiplicative function. Applied to VICs, participants may expect positive reactions from other participants as well as the organiser. These reactions by thirds may be caused by the submitted ideas displayed on the internet platform. For example, taking a look at Dell's Ideastorm VIC, one can observe the intense feedback culture of VICs. Typically, other customers comment on ideas many times in a very friendly way. So, another motive could be the recognition motive.

Proposition 2: Customers use firms' VICs to get recognition for their submitted ideas (recognition motive).

Different open source motivation studies found that open source software programmers also seek to get in contact with peers in order to make new friends or socialise with others (Hertel et al., 2003). When applied to VICs, it is expected that customers also explain and predict this motive to contribute to idea communities. Customers in a VIC may seek to get in contact with other customers in order to make new friends or to socialise. Typically, VICs are equipped with communication and interaction technologies such as chat or email, which enable such socialisation processes. So, a final possible motive is the contact to peers motive.

Proposition 3: Customers use firms' VICs to get in contact with other customers and gain social support or friendship (contact to peers motive).

\section{Research setting}

\subsection{Method}

We focused our research on the 'SAPiens' VIC. SAPiens is VIC (www.sapiens.info) initiated and run by the ERP software producer SAP. SAPiens was launched in the 
summer of 2009 and targeted users of SAP software. Our research seeks to explore the motives that encourage customers of SAP software to participate in SAPiens. Since perceived motivation-related issues can best be expressed by customers participating in the SAPiens community themselves, we conducted a standardised questionnaire survey. We incorporated the motives introduced in the introduction (except the monetary compensation motive ${ }^{2}$ ) as well as the motives derived in Section 2 into the survey. These motives can be categorised, on the one hand, as commonly known motives and, on the other, as motives mediated by IT in VICs, as summarised in Table 1.

Table 1 Assumed customer motives for participating in VICs

\begin{tabular}{ll}
\hline Commonly known motives & Motives mediated by IT in VICs \\
\hline $\begin{array}{l}\text { Fun (measure based on an own item } \\
\text { instrument) }\end{array}$ & $\begin{array}{l}\text { Recognition [measure based on the item } \\
\text { instrument developed by Hars and Ou (2002)] } \\
\begin{array}{l}\text { Intellectual stimulation (measure based on } \\
\text { an own item instrument) }\end{array}\end{array}$ \\
$\begin{array}{l}\text { Self-marketing [measure based on the item } \\
\text { instrument developed by Hars and Ou (2002)] } \\
\text { an own item instrument) }\end{array}$ \\
$\begin{array}{l}\text { Need (measure based on an own item } \\
\text { instrument) }\end{array}$ \\
$\begin{array}{l}\text { Learning (measure based on an own item } \\
\text { instrument) }\end{array}$
\end{tabular}

\subsection{Measures}

We measured the motives listed in Table 1. For the motives that are mediated by IT in VICs, we developed measures for each motive on the basis of item instruments developed by different open source researchers (see Table 1). For the other motives that are commonly known and discussed only on a theoretical basis in product development literature, we developed own item instruments since we did not find any existing scales from previous research that we could rely on. On the whole, we used 21 items to measure the eight motives. Using a rating scale ranging from 1 (strongly disagree) to 5 (strongly agree), customers were asked to rate the degree to which extent each motive motivated them to participate. The questionnaire was structured, tested and consequently adapted to the needs of the target audience.

The questionnaire was pretested by ten experts pursuing doctoral and Master's degrees in information technology and business administration. The objectives of the pretest were to ensure that none of the items was ambiguous, as well as to confirm that the items adequately captured the domain of interest. Expert opinions indicated that the content of the items was valid.

\subsection{Participants}

The questionnaire was implemented using the online-survey service 2aks. Participants of the SAPiens community who submitted at least one idea $(N=149)$ - which indicated that they had participated in collaborative ideation - were provided with a personalised link to the online survey by email. The survey was administered over a period of four weeks. A total of 87 customers provided full answers to the questionnaire representing a $58.39 \%$ 
response rate. Of the 87 customers, $70.11 \%$ were men $(n=61)$ and $60.92 \%(n=53)$ were between the age of 20 and 30 . Concerning the occupation of the customers, $55.17 \%$ $(n=48)$ were students, who were over-represented in the sample. The rest were either SAP consultants or employees who worked with SAP applications once a day or at least a few times a week.

The high number of students is not unusual as the community managers of the SAPiens community recruit many different kinds of SAP users, including students of higher education. However, students are only allowed to take part in the SAPiens community if they can verify degrees from the so-called TERP 10 courses, i.e. advanced SAP training courses for students of higher education training in handling SAP software, and certified and supported by SAP. Because of this, we could be certain of the students' SAP expertise.

Due to the over-representation of students in our data set, we conducted a test to evaluate if the students' answers correspond to those of the group of SAP consultants and the group of employees. In other words, we checked if there are differences in the responses of each of the three groups. Based on Armstrong and Overton's (1977) guidelines, we classified all respondents into these three groups. Analysis of Variance (ANOVA) tests were used to evaluate if the groups' answers systematically differed from each other. These tests revealed no significant bias.

\section{Analysis and results}

As can be seen from Table 2, we tested construct validity of our eight motives and related 21 items based on an exploratory factor analysis. We analysed the items with the help of the statistical software program SPSS 17.0. In order to check whether the data were appropriate for factor analysis, we pre-analysed the Measures of Sampling Adequacy (MSA) for the whole data structure as well as for the individual items. The items PV2 and IH1 showed MSA values lower than 0.5. According to Cureton and D'Agostino's (1983) recommendation deeming that items achieve sampling adequacy if values are equal to or exceed the criterion of 0.5 , these items were excluded within three iterations. After the sixth iteration, all remaining items were above 0.6, and exploratory factor analysis was applicable. We also pre-checked the global MSA value after the third iteration in order to ensure the applicability of explorative factor analysis. With an MSA of 0.729 , the stringent 0.5 criteria of Cureton and D'Agostino (1983) were also met.

The factor analysis resulted in six factors with eigenvalues higher than 1 (varimax rotation). All six factors explained a total of $66.321 \%$ variance. The first factor explained $14.149 \%$ variance, which was mostly determined by all items representing the expected motive of self-marketing. We thus call this factor self-marketing (component 1 in Table 2). The second factor, mostly determined by all 'fun' items, explained $13.887 \%$ variance. The item IH2 also loaded on this factor. According to Raymond (1996), intellectual stimulation can be interpreted as a form of fun. In his empirical study, Raymond (1996) found a participant of an open source community to be a person that "... enjoys the intellectual challenge of creatively overcoming or circumventing limitations ..." when writing an open source software program. Following this argumentation, we accept this item in factor 2 and call this factor fun (component 2 in Table 2). 
Table 2 Rotated component matrix

\begin{tabular}{|c|c|c|c|c|c|c|}
\hline \multirow{2}{*}{$\begin{array}{c}\text { Items } \\
\text { I attended the SAPiens community because ... }\end{array}$} & \multicolumn{6}{|c|}{ Components } \\
\hline & 1 & 2 & 3 & 4 & 5 & 6 \\
\hline \multicolumn{7}{|c|}{ Fun } \\
\hline $\begin{array}{l}\text {... I have fun in working out ideas and creative } \\
\text { solutions. }(S 1)\end{array}$ & 0.065 & 0.660 & 0.268 & 0.065 & 0.117 & -0.039 \\
\hline $\begin{array}{l}\ldots \text { I perceive composing creative ideas as a } \\
\text { kind of self-realisation. }(S 2)\end{array}$ & 0.043 & 0.630 & 0.026 & 0.209 & 0.325 & 0.176 \\
\hline$\ldots$ I take much pleasure in being creative. $(S 3)$ & 0.255 & 0.785 & 0.203 & 0.107 & 0.118 & 0.030 \\
\hline \multicolumn{7}{|c|}{ Intellectual stimulation } \\
\hline $\begin{array}{l}\text {... I am stimulated by generating creative } \\
\text { ideas. }(I H 1)\end{array}$ & \multicolumn{6}{|c|}{$\begin{array}{c}\text { Excluded as item did not achieve } \\
\text { critical MSA value }\end{array}$} \\
\hline $\begin{array}{l}\text {... I am intellectually challenged by developing } \\
\text { creative ideas. (IH2) }\end{array}$ & 0.190 & 0.898 & 0.065 & -0.023 & 0.082 & 0.135 \\
\hline \multicolumn{7}{|c|}{ Recognition } \\
\hline $\begin{array}{l}\ldots \text { I hoped that other customers in SAPiens } \\
\text { would appreciate my idea(s). (ANER } 1)\end{array}$ & 0.423 & 0.236 & 0.048 & 0.610 & 0.087 & 0.120 \\
\hline $\begin{array}{l}\text {... I hoped that other customers participating in } \\
\text { SAPiens would honour my idea(s). (ANER2) }\end{array}$ & 0.110 & 0.452 & 0.407 & 0.418 & 0.096 & 0.006 \\
\hline $\begin{array}{l}\text {... I hoped that SAP would value my idea(s). } \\
\text { (ANER3) }\end{array}$ & 0.415 & 0.089 & 0.131 & 0.710 & 0.191 & 0.284 \\
\hline $\begin{array}{l}\ldots . \text { I hoped that SAP would appreciate my } \\
\text { idea(s). (ANER4) }\end{array}$ & 0.046 & 0.094 & 0.210 & 0.832 & 0.253 & 0.071 \\
\hline \multicolumn{7}{|c|}{ Self-marketing } \\
\hline $\begin{array}{l}\ldots \text { I hoped to show my skills and abilities } \\
\text { through my idea(s) to potential employers. } \\
(S M 1)\end{array}$ & 0.624 & 0.263 & -0.080 & 0.229 & 0.400 & -0.040 \\
\hline $\begin{array}{l}\ldots \text { I hoped to convince SAP of my skills and } \\
\text { abilities through my idea(s). (SM2) }\end{array}$ & 0.762 & 0.214 & -0.121 & 0.337 & 0.160 & 0.216 \\
\hline $\begin{array}{l}\ldots \text { I hoped to demonstrate my skills and } \\
\text { abilities through my idea(s). (SM3) }\end{array}$ & 0.853 & 0.003 & 0.125 & 0.003 & 0.164 & 0.126 \\
\hline \multicolumn{7}{|c|}{ Product improvement } \\
\hline $\begin{array}{l}\ldots \text { I want to give a helping hand in improving } \\
\text { existing SAP software. }(P V 1)\end{array}$ & 0.042 & 0.069 & -0.023 & 0.164 & 0.644 & 0.183 \\
\hline $\begin{array}{l}\text {... I detected a software bug and I wanted to } \\
\text { help fix it. }(P V 2)\end{array}$ & \multicolumn{6}{|c|}{$\begin{array}{l}\text { Excluded as item did not achieve } \\
\text { critical MSA value }\end{array}$} \\
\hline \multicolumn{7}{|c|}{ Need } \\
\hline $\begin{array}{l}\ldots \text { my idea mirrors a need that is not covered } \\
\text { by existing SAP software applications, yet. } \\
(B E D A 1)\end{array}$ & 0.086 & 0.205 & 0.312 & 0.360 & 0.670 & -0.065 \\
\hline $\begin{array}{l}\ldots \text { I wish to tell SAP about my certain } \\
\text { needs that are not covered by existing SAP } \\
\text { applications, yet. }(B E D A 2)\end{array}$ & 0.141 & 0.120 & 0.444 & -0.124 & 0.590 & -0.100 \\
\hline $\begin{array}{l}\ldots \text { I detected a need for a certain SAP software } \\
\text { application and put it into an idea. (BEDA3) }\end{array}$ & 0.129 & 0.364 & 0.024 & 0.194 & 0.578 & 0.110 \\
\hline
\end{tabular}


Table 2 Rotated component matrix (continued)

\begin{tabular}{|c|c|c|c|c|c|c|}
\hline \multirow{2}{*}{$\begin{array}{c}\text { Items } \\
\text { I attended the SAPiens community because ... }\end{array}$} & \multicolumn{6}{|c|}{ Components } \\
\hline & 1 & 2 & 3 & 4 & 5 & 6 \\
\hline \multicolumn{7}{|c|}{ Learning } \\
\hline $\begin{array}{l}\ldots . \text { I hoped to get learning experiences through } \\
\text { the feedback concerning my idea(s). }(L 1)\end{array}$ & 0.413 & 0.138 & 0.426 & -0.011 & -0.102 & 0.677 \\
\hline $\begin{array}{l}\text {... I hoped to learn from discussions with } \\
\text { other customers participating in the SAPiens } \\
\text { community. }(L 2)\end{array}$ & 0.244 & 0.158 & 0.041 & 0.202 & 0.131 & 0.785 \\
\hline \multicolumn{7}{|c|}{ Contact to peers } \\
\hline $\begin{array}{l}\ldots \text { I hoped to get in contact with other SAP } \\
\text { software users in order to talk with them about } \\
\text { my idea(s). }(K Z G 1)\end{array}$ & 0.285 & 0.107 & 0.644 & 0.124 & -0.099 & 0.231 \\
\hline $\begin{array}{l}\ldots \text { I hoped to get in contact with other SAP } \\
\text { software users in order to share experiences } \\
\text { and information. }(K Z G 2)\end{array}$ & 0.314 & 0.348 & 0.482 & 0.222 & -0293 & 0.057 \\
\hline Cronbach's $\alpha$ & 0.857 & 0.860 & 0.772 & 0.852 & 0.779 & 0.804 \\
\hline
\end{tabular}

The item KZG1 loaded on another factor, which explained $11.066 \%$ variance. We accept this as a single-item factor (component 3 in Table 2) and call it contact to peers. On the fourth factor loading, three items directly explained recognition (component 4 in Table 2) $(10.040 \%$ variance $)$. We call the fifth factor representing a $9.989 \%$ expression of variance 'product improvement and enhancement' (component 5 in Table 2), as all need items as well as one of the two product improvement items load on it. We accept that the need and the wish to improve a product can be interpreted as similar aspects. Finally, the sixth factor which explained an additional $7.190 \%$ variance was mostly determined by the supposed learning items. This supposed learning (component 6 in Table 2) appeared to be an independent motive. The items ANER2 and KZG2 were excluded, as their values were below 0.55 , and according to Hair et al.'s (1998) recommendation deeming that items achieve acceptable factor loadings if values are equal to or exceed the criterion of 0.55 . After this complex explanatory factor analysis, the results support the contention that our data set has adequate construct validity.

The reliability of the resulting factors was checked using Cronbach's $\alpha$. A Cronbach's $\alpha$ of 0.7 or higher (Nunnally, 1978) was used as an acceptable value for internal consistency of the measure. Since Cronbach's $\alpha$ of the four factors range from 0.772 to 0.860 (see Table 2), these values support the contention that all factors had adequate reliability. An examination of the validity and reliability of an underlying data set by directly applying explanatory factor analysis and Cronbach's $\alpha$ does not meet modern requirements (Bogazzi et al., 1991), according to Straub et al.'s (2004) recommendation. We then tested our revised data set, based on its six remaining factors and the corresponding 17 items, by applying confirmatory factor analysis and using Amos 18.0. The Goodness of Fit Index (GFI) was 0.951 and the Adjusted Goodness of Fit Index (AGFI) was 0.933. These indices were well over the under-threshold of 0.9, indicating an adequate fit (Browne and Cudeck, 1993). In order to check reliability, we measured all individual item reliabilities, which exceeded the minimum threshold of 0.4 (Homburg and Giering, 1996). Hence, good reliability is confirmed (see Table 3). 
Table 3 Values for Individual Item Reliability, Composite Reliability, and AVE

\begin{tabular}{|c|c|c|c|c|}
\hline Factor & Item & $\begin{array}{l}\text { Individual item } \\
\text { reliability }(\geq 0.4)\end{array}$ & $\begin{array}{c}\text { Composite } \\
\text { reliability }(\geq 0.6)\end{array}$ & $A V E(\geq 0.5)$ \\
\hline \multirow{4}{*}{ Self-marketing } & MO_SM_1 & 0.557 & \multirow{4}{*}{0.860} & \multirow{4}{*}{0.608} \\
\hline & MO_SM_2 & 0.800 & & \\
\hline & MO_SM_3 & 0.564 & & \\
\hline & MO_KZG_1 & 0.503 & & \\
\hline \multirow{4}{*}{ Fun } & MO_S_1 & 0.433 & \multirow{4}{*}{0.871} & \multirow{4}{*}{0.639} \\
\hline & MO_S_2 & 0.577 & & \\
\hline & MO_S_3 & 0.828 & & \\
\hline & MO_IH_2 & 0.647 & & \\
\hline Contact to peers & MO_KZG_1 & 0.490 & 0.778 & 0.552 \\
\hline \multirow{3}{*}{ Recognition } & MO_ANER_1 & 0.677 & \multirow{3}{*}{0.860} & \multirow{3}{*}{0.676} \\
\hline & MO_ANER_3 & 0.927 & & \\
\hline & MO_ANER_4 & 0.424 & & \\
\hline \multirow{4}{*}{$\begin{array}{l}\text { Product } \\
\text { improvement } \\
\text { and enhancement }\end{array}$} & MO_BEDA_1 & 0.725 & \multirow{4}{*}{0.781} & \multirow{4}{*}{0.574} \\
\hline & MO_BEDA_2 & 0.427 & & \\
\hline & MO_BEDA_3 & 0.647 & & \\
\hline & MO_PV_1 & 0.418 & & \\
\hline \multirow{2}{*}{ Learning } & MO_L_1 & 0.725 & \multirow{2}{*}{0.698} & \multirow{2}{*}{0.536} \\
\hline & MO_L_2 & 0.626 & & \\
\hline
\end{tabular}

Further, all factors showed good values for composite reliabilities as well as for Average Variance Explained (AVE); thus, convergent validity can be assumed (see Table 3). Values of 0.6 regarding the composite reliability and 0.5 for the AVE can be seen as minimum values for indicating a good measurement quality (Bagozzi and Yi, 1988). The discriminant validity of the factors was checked by using the Fornell-Larcker criteria, which claims that one factor's AVE should be higher than its squared correlation with every other factor (Fornell and Larcker, 1981). Tables 3 and 4 depict that discriminant validity can be assumed for the six factors. In sum, our data set was successfully validated using both exploratory and confirmatory factor analysis.

Table 4 Squared multiple correlations

\begin{tabular}{lcccccc}
\hline & $\begin{array}{c}\text { Self- } \\
\text { marketing }\end{array}$ & Fun & $\begin{array}{c}\text { Contact } \\
\text { to peers }\end{array}$ & Recognition & $\begin{array}{c}\text { Prod Imp }+ \\
\text { Enh }\end{array}$ & Learning \\
\hline Self-marketing & & 0.00289 & 0.0729 & 0.2401 & 0.0729 & 0.2704 \\
Fun & 0.0289 & & 0.0324 & 0.0225 & 0.00289 & 0.0324 \\
Contact to peers & 0.0729 & 0.0324 & & 0.0729 & 0.1156 & 0.1444 \\
Recognition & 0.2401 & 0.0225 & 0.0729 & & 0.1089 & 0.2116 \\
Prod Im + Enh & 0.0729 & 0.00289 & 0.1156 & 0.1089 & & 0.0441 \\
Learning & 0.2704 & 0.0324 & 0.1444 & 0.2116 & 0.0441 & \\
\hline
\end{tabular}




\section{Discussion}

The purpose of our empirical study was to explore customers' motives for engaging in IT-enabled ideation within VICs, especially motives that are directly ascribed to IT enabling of customer ideation. Overall, the results suggest that there are six motives: selfmarketing, fun, contact to peers, recognition, product improvement and enhancement, and learning. Our empirically identified motives can be divided into two classes. Regarding our first research question, there are motives that refer to customer-based ideation per se. Having fun when generating and collaboratively elaborating on ideas (fun motive), wishing to improve or enhance products (product improvement and enhancement motive) and expanding individual knowledge base and expertise (learning motive) are well known from studies of customer motivation for participating in lead user workshops and focus groups, e.g. Thomas and Dunn (1994), Nambisan (2002), Bateson (1983) and von Hippel (1986). Our research results indicate that these motivation factors are also relevant in IT-mediated ideation within VICs.

Regarding our second research question, there is a second group of motives: selfmarketing, contact to peers and recognition. These motives are directly ascribed to IT enabling of customer-based ideation, namely IT-based idea management systems' ability to support visualisation of ideas, to give direct feedback on customer ideas and to support customer communication (Sandström and Bjork, 2010). Concerning the self-marketing motive, customers perceive the fact that customer ideas are prominently visualised together with the idea submitter's name to the idea management system as a chance to demonstrate personal capabilities and skills mirrored in their ideas. This IT-mediated opportunity is a way of signalling which one party transmits underlying information about itself to another party. Signalling is discussed in contract theory (Bolton and Dewatripont, 2005) or Akerlof's (1970) market for lemon. This becomes relevant in the presence of asymmetric information, which says that in some economic transactions, buyers of transactions have no information or insufficient information concerning the seller's offer before the transaction happens. Because of this, buyers have considerable uncertainties concerning the transaction. In this context, signalling is a way of getting around the problem of asymmetric information by allowing the seller to send signals that reveal some piece of relevant information to the buyer, thereby diminishing their uncertainties. For example, in the job-market-signalling model, potential employees send a signal about their experiences and skills to the employer through former job references or certificates of schooling (Spence, 1973). Applied to VICs, by submitting ideas, customers are able to send signals of competence, knowledge and skills to the firm that runs a VIC, thereby supporting a search for job opportunities at the firm. Audiences of such signals could also be hundreds of other customers in other firms. In general, submitting ideas, or generally speaking, participating in VICs, is therefore perceived as a good channel for self-marketing. This overlaps with insights gained from open source motivation research. For example, Hars and Ou (2002) as well as Hertel et al. (2003) found that open source software programmers participate in open source software communities in order to demonstrate their capabilities and skills through submission of code. Audiences of such signals are other programmers, but mainly software companies which often engage in such projects. Participating in open source projects, therefore, can be a good channel for self-advertisement for programmers seeking new job opportunities.

Regarding the recognition motive, there are various IT-based mechanisms implemented allowing customer to praise submitted ideas in the idea management system 
of VICs. First, there are rating mechanisms that allow customers to rate submitted ideas. For example, there are simple binary rating scales (thumbs-up, thumbs-down) or 5-star rating scales, which enable customers to quickly share their evaluation. Other VICs implement a voting mechanism attached to each submitted idea that displays the number of votes an idea has received. Second, there is a review mechanism that allows customers to write a comment or feedback regarding ideas using certain review forms. Overall, with the help of such IT-based mechanisms, idea submitters can receive recognition from customers participating in VICs. In psychological theory, recognition is derived from an individual's desire for fame and esteem (Maslow, 1987; Holmström, 1999). Positive recognition for, e.g. a certain piece of work, is described to be self-reinforcing, as positive feedback enhances motivation for expending additional effort in this or future work (Boggiano and Pittman, 1992). As our results reveal, this pattern is in line with VICs. Idea submitters feel proud when other customers acknowledge their ideas openly in the community and they perceive this recognition as an additional incentive for creating new ideas or elaborating existing ideas. The recognition motive is also discussed in the open source community context (Hars and Ou, 2002; Shah, 2005). Recognition relates to reactions of significant others, such as other programmers. Motivation to contribute to an open source community is higher the more positive the expected reactions of significant others are, weighted by the perceived importance of these significant others (Hars and Ou, 2002). The vehicles that transport recognition within VICs are IT-enabled idea management systems (Sandström and Bjork, 2010), which include the above-mentioned rating, voting and commenting features. So, the underlying recognition mechanism in VICs which encourages customer participation is an important motivation that is enabled directly with the help of information technologies.

The contact to peers motive is linked to getting in contact with other customers in order to make new friends or to interact with others in the virtual environment of a VIC. Several open source motivation studies refer to this, too. For example, Ghosh et al. (2002) and Hertel et al. (2003) found that open source software programmers seek to contact other programmers in order to make new friends or socialise. The reason why communication and interaction among customers is enabled is, once again, information technology. In VICs, such as Dell's Ideastorm or SAP's SAPiens, email or chat systems allow synchronous or asynchronous communication independent of time and place. This allows for interaction not only for collaborating on ideas, but also for interpersonal communication.

Table 5 Motives enabled by information technologies

\begin{tabular}{lll}
\hline \multicolumn{2}{c}{ Motive } & IT that enables related motive \\
\hline Self-marketing & $\begin{array}{l}\text { Self-advertisement through } \\
\text { submitted ideas }\end{array}$ & $\begin{array}{l}\text { Visualisation of ideas in verbal and/or visual } \\
\text { manner }\end{array}$ \\
\hline \multirow{2}{*}{ Recognition } & $\begin{array}{l}\text { Getting recognition or positive } \\
\text { feedback on submitted ideas }\end{array}$ & $\begin{array}{l}\text { Rating mechanism, such as thumbs-up, } \\
\text { thumbs-down or 5-star rating scales } \\
\text { Voting mechanism } \\
\text { Idea review mechanism }\end{array}$ \\
\hline Contact to peers & $\begin{array}{l}\text { Getting in contact with other } \\
\text { customers for social interaction }\end{array}$ & $\begin{array}{l}\text { Email system } \\
\text { Chat system }\end{array}$ \\
\hline
\end{tabular}

To summarise, the mentioned information technologies, such as idea visualisation and review mechanisms, implemented in idea management systems of VICs are the reason 
why new customer motives, namely self-marketing, recognition and contact to peers, for participating in firms' ideation processes arose. Table 5 summarises the discussed findings.

\section{Conclusion}

\subsection{Implications for theory}

Analogous to Dibbern et al. (2008), one can distinguish several kinds of theoretical contributions to research depending on the goal and type of the underlying theory. These authors distinguish (among others) between theory confirmation and theory extension (Dibbern et al., 2008). In accordance with theory conformation, we provide a theoretical confirmation as follows. Our identified motives fun, product improvement and enhancement, and learning are well known from prior studies of customer motivation for participating in lead user workshops and focus groups, e.g. Thomas et al. (1994), Nambisan (2002), Bateson (1983) and von Hippel (1986). Our results indicate that these motivation factors are also relevant in IT-mediated ideation within VICs. By empirically validating the existence of these motives in VICs, we contribute new insights to the general body of knowledge regarding motivation for participation in customer-based ideation for product innovation.

Moreover, motives for participating in conventional ideation have been exhaustively researched. But so far, it was unclear, which motives lead to participation in a VIC. We found evidence for motives that arise directly due to the VIC underlying idea management system's ability to support visualisation of customers' ideas, to give feedback on ideas and to support customers' social interactions. As a result, VICs are perceived as a way for customers to demonstrate personal capabilities and skills (self-marketing-motive), to receive recognition from third parties (recognition-motive) and to facilitate social communication and interaction with a large amount of peers (contact to peers motive). Thus, our results contribute to theory by offering new specific insights concerning motivation for participation in customer-based ideation for product innovation.

\subsection{Implications for practice}

We found evidence that general motivations for participation in customer-based ideation do not sufficiently explain customers' motives for participating in VICs. Existing ITbased VIC features (see Table 5) support new kinds of customer motivation. But these features are still few, so knowing that self-marketing, recognition and the wish for contacting peers are relevant motivation factors is a valuable insight for firms to draw on to systematically design and implement further IT-enabled features into their VICs that will encourage customers to participate. This, in turn, will lead to higher numbers of customers participating and contributing ideas to VICs.

For example, implementing a profile site for customers that display participants' curriculum vitae, competencies, skills and experiences - as for example known from social network communities like Facebook - would be a good IT-enabler driving the selfmarketing motive. Furthermore, the community platform could offer a personal site where customers can display their personal collection of ideas. Such an idea collection 
would intensify the self-marketing effect as the collection as a whole can represent the idea owner's competences and creativity potential more efficiently. In this way, customers may be more readily identified as experts in a special area of interest, which in turn would enhance their reputation much faster. These are only two examples for future IT components that would activate self-marketing, recognition and contact to peers motives. Certainly, there are a lot more to explore.

\subsection{Limitations}

A limitation of this study involves the sample of our motivation survey. Our sample size was relatively small. Despite the fact that the size was certainly adequate for applying factor analysis, our results would have been more meaningful with a bigger sample size. For this reason, our results might impose some limitations concerning the generalisability. Future research should test and validate our approach by collecting more data sets.

\section{References}

Afuah, A.N. and Tucci, C. (2012) 'Crowdsourcing as a solution to distant search', Academy of Management Review, Vol. 37, pp.355-375.

Akerlof, G.A. (1970) 'The market for "lemons": quality uncertainty and the market mechanism', Quarterly Journal of Economics, Vol. 84, No. 3, pp.488-500.

Armstrong, S. and Overton, T. (1977) 'Estimating nonresponse bias in mail surveys', Journal of Marketing Research, Vol. 14, No. 3, pp.396-402.

Bagozzi, R.P. and Yi, Y. (1988) 'On the evaluation of structural equation models', Journal of the Academy of Marketing Sciences, Vol. 16, No. 1, pp.74-94.

Bateson, J.E. (1983) 'The self-service customer: empirical findings', in Berry, L. and Upah, G. (Eds): Emerging Perspectives in Service Marketing, American Marketing Association, Chicago, IL, pp.50-53.

Bilgram, V., Brem, A. and Voigt, K-I. (2008) 'User-centric innovations in new product development: systematic identification of lead users harnessing interactive and collaborative online-tools', International Journal of Innovation Management, Vol. 12, No. 3, pp.419-458.

Bogazzi, R., Yi, Y. and Phillips, L.W. (1991) 'Assessing construct validity in organizational research', Administrative Science Quarterly, Vol. 36, pp.421-458.

Boggiano, A.K. and Pittman, T.S. (1992) Achievement and Motivation: A Social-Developmental Perspective, Cambridge University Press, New York.

Bolton, P. and Dewatripont, M. (2005) Contract Theory, MIT Press, Cambridge, MA.

Browne, M.W. and Cudeck, R. (1993) 'Alternative ways of assessing model fit', in Bollen, K.A. and Long, J.S. (Eds): Testing Structural Equation Models, Sage, Newbury Park, CA, pp.136-162.

Chesbrough, H. (2003) 'The era of open innovation', Sloan Management Review, Vol. 44, No. 4, pp.35-41.

Cureton, E.E. and D’Agostino, R.B. (1983) Factor Analysis: An Applied Approach, Hillsdale, New Jersey.

Di Gangi, P.M. and Wasko, M. (2009) 'Steal my idea! Organizational adoption of user innovations from a user innovation community: a case study of Dell ideastorm', Decision Support Systems, Vol. 48, pp.303-312.

Dibbern, J., Winkler, J. and Heinzl, A. (2008) 'Explaining variations in client extra costs between software projects offshored to India', MIS Quarterly, Vol. 32, No. 2, pp.333-366. 
Fern, E.F. (1982) 'The use of focus groups for idea generation: the effects of group size, acquaintanceship, and moderator on response quantity and quality', Journal of Marketing Research, Vol. 19, pp.1-13.

Fornell, C. and Larcker, D.F. (1981) 'Evaluating structural equation models with unobservable variables and measurement error', Journal of Marketing Research, Vol. 18, No. 2, pp.39-50.

Ghosh, R.A., Krieger, B., Glott, R. and Robles, G. (2002) The Free/Libre and Open Source Software Developers Survey and Study - FLOSS, International Institute of Infonomics, University of Maastricht.

Hair, J.F., Black, W.C., Babin, B.J. and Anderson, R.E. (1998) Multivariate Data Analysis, Prentice Hall, Upper Saddle River, NJ.

Hars, A. and $\mathrm{Ou}, \mathrm{S}$. (2002) 'Working for free? Motivations for participating in open-source projects', International Journal of Electronic Commerce, Vol. 6, No. 3, pp.25-39.

Hertel, G., Niedner, S. and Herrmann, S. (2003) 'Motivation of software developers in open source projects: an internet-based survey of contributors to the Linux kernel', Research Policy, Vol. 32, No. 1, pp.1159-1177.

Hoch, D., Roeding, C., Purkert, G. and Lindner, S.K. (1999) Secrets of Software Success, Harvard Business School Press, Boston, MA.

Holmström, B. (1999) 'Managerial incentive problems: a dynamic perspective', Review of Economic Studies, Vol. 66, pp.169-182.

Homburg, C. and Giering, A. (1996) 'Konzeptionalisierung und Operationalisierung komplexer Konstrukte: Ein Leitfaden für die Marketingforschung', Marketing Zeitschrift für Forschung und Praxis, Vol. 18, No. 1, pp.5-24 (in German).

Leimeister, J.M. (2012) Dienstleistungsengineering und -management, Springer Gabler, Berlin/Heidelberg (in German).

Leimeister, J.M. (2014) Collaboration Engineering, Springer Gabler, Berlin/Heidelberg.

Leimeister, J.M., Huber, M., Bretschneider, U. and Krcmar, K. (2009) 'Leveraging crowdsourcing: activation-supporting components for IT-based ideas competitions', Journal of Management Information Systems, Vol. 26, No. 1, pp.197-224.

Magnusson, P.R., Kristensson, P. and Hipp, C. (2009) 'Exploring the ideation patterns of ordinary users: the case of mobile telecommunications services', International Journal of Product Development, Vol. 11, Nos. 3-4, pp.289-309.

Maslow, A.H. (1987) Motivation and Personality, Harper \& Row, New York.

Mills, P.K. (1986) Managing Service Industries, Ballinger, Cambridge, MA.

Moors, E.H.M., Boon, W.P.C., Nahuis, R. and Vandeberg, R.L.J. (2008) 'User-producer interactions in emerging pharmaceutical and food innovations', International Journal of Innovation Management, Vol. 12, No. 3, pp.459-487.

Nambisan, S. (2002) 'Designing virtual customer environments for new product development: toward a theory', Academy of Management Review, Vol. 27, No. 3, pp.392-413.

Nunnally, J.C. (1978) Psychometric Theory, McGraw-Hill, New York.

Öberg, C. (2010) 'Customer roles in innovations', International Journal of Innovation Management, Vol. 14, No. 6, pp.989-1011.

Raymond, E.S. (1996) The New Hacker's Dictionary, The MIT-Press, Cambridge, MA.

Sandström, C. and Bjork, J. (2010) 'Idea management systems for a changing innovation landscape', International Journal of Product Development, Vol. 11, Nos. 3-4, pp.310-324.

Shah, S.K. (2005) Motivation, Governance \& the Viability of Hybrid Forms in Open Source Software Development, Working Paper, University of Washington.

Spence, M. (1973) 'Job market signaling', Quarterly Journal of Economics, Vol. 87, No. 3, pp.355-374.

Straub, D., Boudreau, M-C. and Gefen, D. (2004) 'Validation guidelines for IS positivist research', Communications of the Association for Information Systems, Vol. 13, pp.380-427. 
Thomas, C. and Dunn, D.T. (1994) 'Partnering with customers', Journal of Business \& Industrial Marketing, Vol. 9, No. 1, pp.34-40.

von Hippel, E. (1986) 'Lead users: a source of novel product concepts', Management Science, Vol. 32, No. 7, pp.791-805.

Zogaj, S. and Bretschneider, U. (2012) 'Customer integration in new product development: a literature review concerning the appropriateness of different customer integration methods to attain customer knowledge', Proceedings of the 20th European Conference on Information Systems (ECIS), 10-13 June, Barcelona, Spain.

\section{Notes}

1 We use the terms SAP customer and SAP user synonymously, as, in general, software customers are also software users. We know that in the case of SAP, the ones who 'buy' the software are typically not the ones who use the software. However, in order to ease this circumstance, we use both terms synonymously.

2 We excluded monetary compensation, as this motive is not relevant in the context of VICs since customers participating in VICs typically do not receive any monetary compensation. 